\title{
LEVANTAMENTO QUANTITATIVO E QUALITATIVO DE INDIVÍDUOS ARBÓREOS PRESENTES NAS VIAS DO BAIRRO DA RONDA EM PONTA GROSSA-PR
}

\author{
Talita Oliveira de Miranda; Silvia Méri Carvalho² \\ (recebido em 14.05. 2009 e aceito para publicação em 22.09.2009)

\section{RESUMO}

Este trabalho integra um projeto de levantamento das condições da arborização urbana de vias públicas do município de Ponta Grossa-PR e analisou, no bairro da Ronda, 1.891 indivíduos arbóreos presentes em 79 vias, com total de 86 espécies e 37 famílias. Dentre as espécies $64,4 \%$ são exóticas e $35,6 \%$ nativas. A espécie exótica presente em maior número é o Ligustrum lucidum W. T. Aiton (Ligustro) com 20,7\%, e a espécie nativa com maior frequência é a Schinus terebinthifolius Raddi. (Aroeira) com 7,63\%. As principais famílias encontradas foram Oleaceae (20,7\%) e a Fabaceae (12\%). Os indivíduos arbóreos foram classificados de acordo com o tipo de poda e outros conflitos, bem como o porte das árvores em relação ao tamanho das calçadas. Foi realizado um registro fotográfico das espécies mais freqüentes, além de relacionar as vias com potencial para futuro adensamento da arborização no bairro. Por meio dos índices de Similaridade, Diversidade e Abundância foram comparados os quatro bairros do município de Ponta Grossa que já possuem inventário da arborização viária. O bairro da Ronda apresenta alto índice de diversidade $(25,9)$ e abundância (55 árvores por Km de via).

Palavras-chave: Arborização Urbana; Nativas; Exóticas.

\footnotetext{
${ }^{1}$ Bacharel em Geografia - Universidade Estadual de Ponta Grossa (UEPG).Rua Peroba, n. 51, Jardim Eldorado, Caixa Postal 1071. Carambeí - PR. CEP: 84.145-000. E-mail: talitamiranda52@hotmail.com;

${ }^{2}$ Doutora em Geografia - Docente do Departamento de Geociências/Mestrado em Gestão do Território - Universidade Estadual de Ponta Grossa (UEPG) silviameri@brturbo.com.br
} 


\title{
SURVEY QUANTITATIVE AND QUALITATIVE TREES THESE INDIVIDUALS IN THE NEIGHBORHOOD OF RONDA IN PONTA GROSSA-PR
}

\begin{abstract}
This work includes a project to survey the conditions of urban afforestation of public roads in the municipality of Ponta Grossa-PR, and analyzed in the neighborhood of the round, 1,891 individuals in 79 trees pathways, with a total of 86 species and 37 families. Among the exotic species are $64.4 \%$ and $35.6 \%$ native. The exotic species present in greater numbers is the Ligustrum lucidum W. T. Aiton (privet) with $20.7 \%$, and the native species most often is the Schinus terebinthifolius Raddi. (Aroeira) with 7.63\%. The main families were Oleaceae (20.7\%) and Fabaceae (12\%). Individuals trees were classified according to the type of pruning and other conflicts as well as the size of the trees on the size of sidewalks. Questionnaires were applied to the local population. This was a photographic record of the most frequent species, and ways to relate with the potential for future density of trees in the neighborhood. Through the indices of similarity, diversity and abundance were compared the four districts of the city of Ponta Grossa already have inventory in stock road. The district round of shows high diversity index (25.9) and abundance (55 trees per km of track).
\end{abstract}

Key-Words: Urban Afforestation; Native; Exotic; Ronda. 


\section{INTRODUÇÃO}

A árvore é o vegetal mais presente na vida e no ciclo histórico do homem. No início era usada como combustível para alimentar as fogueiras dentro das cavernas, passando, posteriormente, a ser usada como arma de caça, implemento agrícola, componente das casas e, hoje está inserida no cotidiano do homem em vários momentos e nas mais diversas formas (SANTOS e TEIXEIRA, 2001).

De acordo com esses autores, a simples presença de árvores nas vias não qualifica arborização, frequentemente encontram-se árvores quebradas, disformes, doentes e até mortas. Considera-se arborização o conjunto de exemplares arbóreos de forma e porte compatível com o espaço sem problemas físicos ou sanitários.

Arborização urbana viária, referencial de análise deste trabalho, está incluída dentro do contexto da arborização urbana como sendo aquela que acompanha as vias públicas, estando em calçadas, canteiros centrais, rotatórias e trevos de conversão (CAVALHEIRO, 1991).

A pobreza em espécies nas vias acarreta maior suscetibilidade a pragas e doenças. Em uma rua onde se utiliza um maior número de espécies é possível que se tenha flores, frutos e folhas o ano todo, porque cada espécie tem seu período de florescimento, frutificação e forma de renovação foliar.

Afim de buscar uma maior heterogeneidade é relevante a elaboração de um plano de Arborização Urbana, pois por meio desse, obtém-se um diagnóstico preciso das vias arborizadas, quais as espécies encontradas nessa, para então refletir sobre novas formas de pensar a cidade, de acordo com a legislação pertinente, e que atenda aos anseios da população e ao equilíbrio ambiental.

A falta de técnicos especializados em arborização, aliado a falta de informações e pesquisa, têm feito com que muitos transtornos ocorram. A arborização de um local sem planejamento pode acarretar em muitos conflitos com a estrutura urbana, como por exemplo, a pressão exercida pelas raízes, que provoca trincas, e pode comprometer grandes extensões de piso, além de árvores de grande porte em calçadas estreitas podendo prejudicar a estrutura de muros, impedindo a visibilidade de placas de trânsito,entre outros.

Outro fator importante para um planejamento é a prioridade que se deve dar as plantas nativas, pois as espécies exóticas podem causar diversos danos ao ambiente, como a perda da biodiversidade, modificações nos ciclos e características naturais dos ecossistemas atingidos, alteração fisionômica da paisagem natural e, algumas vezes consequências econômicas vultuosas (ZILLER, 2001). 
No ambiente urbano, a relação árvore e poda está tão arraigada na mente das pessoas que estas acreditam realizar a melhor prática. No entanto, a poda de árvores é uma agressão, pois elas possuem uma forma estrutural bem definida e poucos mecanismos de defesa (SEITZ, 1990). A poda drástica é antieconômica, uma vez que, depois de sua execução, ocorre uma super brotação, nas proximidades do corte, de ramos que tendem a uma posição ascendente (BALENSIEFER,1987).

Segundo Bortoleto (2004) as árvores urbanas não devem ser podadas. É recomendada apenas a poda de formação, para que a muda atinja um fuste de mais ou menos dois metros de altura e o seu plantio correto, para não haver mutilação. Entretanto, pode ser realizada em caso de galhos secos, doentes ou mal colocados.

Este trabalho teve como objetivo elaborar um inventário da arborização urbana de vias públicas do bairro da Ronda em Ponta Grossa-PR, identificando espécies nativas e exóticas presentes e suas condições sanitárias. Buscou contribuir para o diagnóstico geral da arborização viária da cidade, a partir da comparação com outros inventários realizados por meio dos índices de similaridade, diversidade e abundância, fornecendo subsídios ao poder público para elaboração de um Plano de Arborização Urbana.

\section{MATERIAIS E MÉTODOS}

Escolheu-se o bairro da Ronda dando sequência a ordem estabelecida no projeto principal sobre a arborização da cidade de Ponta Grossa. O bairro apresenta uma proximidade com o centro da cidade, sendo um local de destaque para o poder público, pois neste encontra-se a Prefeitura Municipal, a Câmara Municipal, $1^{0}$ Batalhão da Polícia Militar, o Departamento Nacional de Trânsito, o terminal Rodoviário, entre outros, tende a ser uma área apropriada para sensibilizar os governantes quanto a importância de se fazer um planejamento arbóreo.

O Bairro da Ronda localiza-se na área sudoeste do município, abriga dentro de seus limites oito vilas, sendo elas: Vila Antunes Duarte, Esperança, Felicidade, Moisés Lerner, Peixoto, Parque Auto Estrada, Ricci e Ronda.

Segundo o Censo Demográfico de 2000, a população total do bairro é de 9.182 habitantes, que residem em 2.660 domicílios (IBGE, 2008).

No Bairro da Ronda encontra-se ainda uma extensa área verde, o Parque Municipal Mata Boca da Ronda, localizado na porção norte do bairro, cuja cobertura vegetal caracteriza-se por uma associação secundária de Floresta Ombrófila Mista com capoeiras. (TAKEDA et.al., 1998). 
Para a presente pesquisa foram realizados levantamentos bibliográficos sobre a temática arborização urbana e a utilização da base cartográfica da Prefeitura Municipal de Ponta Grossa (2004), para delimitação da área de estudo.

Foram identificados somente indivíduos arbóreos presentes nas vias, tomando como base indivíduos com PAP (Perímetro na altura do peito) acima de $20 \mathrm{~cm}$, acompanhando a metodologia adotada em trabalhos anteriores (QUADROS, 2005; SILVA, 2006 e VILELA, 2007) que compõe projeto que visa inventariar toda arborização urbana viária da cidade de Ponta Grossa. O material botânico coletado foi identificado no Herbário da Universidade Estadual de Ponta Grossa.

Para a preparação do trabalho de campo foi utilizado o software Arc View 3.2, do Laboratório de Geoprocessamento do Departamento de Geociências da Universidade Estadual de Ponta Grossa, obtendo-se a delimitação da área de estudo e das vias arborizadas. Na etapa subseqüente foram elaboradas planilhas (Tabela 1) para a identificação das espécies, número de indivíduos arbóreos por vias, estado geral em que esses se encontram.

TABELA 1: Planilha utilizada para catalogar os indivíduos arbóreos por via do bairro da Ronda, 2008.

\begin{tabular}{|c|c|c|c|c|c|c|c|c|c|c|c|}
\hline \multicolumn{12}{|c|}{$\begin{array}{l}\text { RUA: XXXXX, SENTIDO CENTRO-BAIRRO OU BAIRRO-CENTRO } \\
\text { INÍCIO: NOME DA VIA } \\
\text { FINAL : NOME DA VIA }\end{array}$} \\
\hline \multicolumn{6}{|c|}{ LADO ESQUERDO } & \multicolumn{6}{|c|}{ LADO DIREITO } \\
\hline Árvore & Espécie & Tipo Poda & $\begin{array}{l}\text { Altura } \\
\text { (m) }\end{array}$ & $\begin{array}{c}\text { Calçada } \\
\text { (m) }\end{array}$ & Conflito & Árvore & Espécie & Tipo Poda & $\begin{array}{l}\text { Altura } \\
(\mathrm{m})\end{array}$ & $\begin{array}{c}\text { Calçada } \\
\text { (m) }\end{array}$ & Conflito \\
\hline$N^{0} 1$ & nome & $\begin{array}{l}\text { Leve boa } \\
\text { Leve ruim } \\
\text { Pesada } \\
\text { boa } \\
\text { Pesadaruim } \\
\text { Radical }\end{array}$ & & & $\begin{array}{c}\text { Rede } \\
\text { Elétrica } \\
\text { Muro } \\
\text { Calçada }\end{array}$ & $\mathrm{N}^{0} 1$ & nome & $\begin{array}{l}\text { Leve boa } \\
\text { Leve ruim } \\
\text { Pesada } \\
\text { boa } \\
\text { Pesadaruim } \\
\text { Radical }\end{array}$ & & & $\begin{array}{c}\text { Rede } \\
\text { Elétrica } \\
\text { Muro } \\
\text { Calçada }\end{array}$ \\
\hline
\end{tabular}

Com relação a poda, utilizou-se a metodologia adaptada de Volpe-Filik, Silva e Lima (2007), onde os indivíduos foram classificados de acordo com o tipo de poda que sofreram:

- Leve: realizada em galhos com diâmetro menor que $5 \mathrm{~cm}$;

- Pesada: diâmetro maior que $5 \mathrm{~cm}$;

- Boa: preservou crista e colar;

- Ruim: não preservou crista;

- Poda Radical: não preservou crista e colar, deixou somente o tronco.

Foi analisado o porte das árvores em relação ao tamanho das calçadas, adaptando a metodologia do Manual Técnico de Arborização Urbana, Secretaria do Verde e Meio Ambiente da Prefeitura da cidade de São Paulo (SÃO PAULO, 2006): 
- Calçadas de 2 a 3m: comportam árvores de médio porte - até $6 \mathrm{~m}$ de altura;

- Calçadas maiores de 3m comportam árvores de grande porte - maiores de 6m.

Também foram analisados conflitos com muro, rede elétrica e calçadas.

Foi realizado um registro fotográfico contendo as dez espécies arbóreas com maior freqüência, sendo relacionadas as vias com potencial para futuro adensamento da arborização no bairro, levando-se em conta a largura das calçadas e a proporção do tamanho da via com a quantidade de árvores.

Foi realizada uma comparação entre os quatro bairros que já possuem inventário da arborização viária por meio de três índices: Similaridade, Diversidade e Abundância (ROSSATO, TSUBOY e FREI, 2008).

- Índice de Similaridade: pode ser identificado por várias fórmulas, optou-se pela de Jaccard por ser de fácil interpretação.

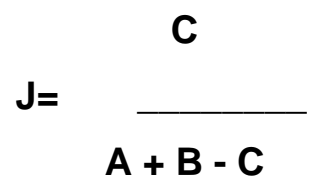

Onde:

- J: índice de Jaccard;

- A: número de espécies na comunidade a;

- B: número de espécies na comunidade b;

- C: número de espécies em comum entre as duas comunidades (GARCIA, LOBOFARIA, 1993).

- Índice de Diversidade: proposto por Margalef (1951), em que:

$$
\text { Alfa }=(S-1) / \log N
$$

Onde:

- Alfa = Índice de diversidade;

- S = número de espécies;

- $\mathbf{N}$ = número de indivíduos (COSTA, LINK e MEDINA, 2007).

Os valores inferiores a 2,0 são considerados como denotando áreas de baixa diversidade e valores superiores a 5,0 são considerados como indicador de grande biodiversidade.

- Índice de Abundância: indica quantas árvores existem por $\mathrm{Km}$ de rua.

Utilizando a base cartográfica da PMPG (2004), escala 1: 15000 foram verificados por meio do software livre Kosmo 1.2 quantos quilômetros de rua há por bairro, em seguida, dividido o número de indivíduos arbóreos pela extensão das vias de rua de cada comunidade. (Adaptado de ROSSATO; TSUBOY e FREI, 2008). 


\section{RESULTADOS E DISCUSSÃO}

A importância da arborização pode ser constatada através das leis existentes no município de Ponta Grossa, por meio do Plano Diretor, que é o principal instrumento disciplinador da arborização da cidade, estando este aprovado sob a Lei n 8.663 de 09 de Outubro de 2006.

O projeto de Lei do Zoneamento de Uso e ocupação do solo atualizou a legislação que dispõe sobre este tema no Município de Ponta Grossa, sendo que em seu $1^{\circ}$ capítulo, artigo $2^{\circ}$, tem como um de seus objetivos - IV Garantir padrões mínimos de qualidade ambiental nas áreas urbanas do município.

A lei $n^{\circ} 6.326$ que dispõe sobre loteamentos em seu Art. $8^{\circ}$ estabelece que para haver a aprovação de projetos de arruamento ou loteamento, a Prefeitura deverá indicar nas plantas o plano de arborização de vias públicas.

A Lei Ordinária no 9632/2008 de 18/07/2008 institui a campanha permanente de incentivo à arborização de ruas, praças e jardins do Município de Ponta Grossa.

Outra lei aprovada foi a Lei Ordinária no 9599/2008 de 30/07/2008 que acrescenta o art. 16-A na Lei $n^{\circ}$ 4.712/92 - Código de Posturas do Município, com a seguinte redação;

Art. 16-A - As ruas e avenidas devem ter arborização nas duas faces e uma árvore para cada lote ou no mínimo a cada 12,00m (doze metros). O Poder Executivo Municipal regulamentará a presente lei no prazo de 60 (sessenta) dias a contar da sua vigência (PMPG, 2008).

Com relação a arborização das vias públicas do bairro da Ronda, foram analisados 1.891 indivíduos arbóreos presentes em 79 vias, representados por 86 espécies e 37 famílias. Dentre as espécies 64,4\% (1.104 indivíduos) são exóticas e 35,6\% (609 indivíduos) nativas, sendo que 42 indivíduos arbóreos estavam mortos, 49 não puderam ser identificadas devido à poda radical e 87 foram identificados apenas em nível de família devido à ausência de flores e/ou frutos (Tabela 2). 
TABELA 2: Espécies inventariadas nas vias do bairro da Ronda em Ponta Grossa$\mathrm{PR} / 2008$, quantidade de indivíduos por espécies (NI) e sua freqüência (Fr).

\begin{tabular}{|c|c|c|c|c|c|}
\hline Nome Popular & Nome Científico & Família & Origem & NI & Fr.\% \\
\hline Ligustro & Ligustrum lucidum W. T. Aiton & Oleaceae & Exótica & 357 & $20,7 \%$ \\
\hline Aroeira & Schinus terebinthifolia Raddi. & Anacardiaceae & Nativa & 131 & $7,63 \%$ \\
\hline Extremosa & Lagerstroemia indica L. & Lythraceae & Exótica & 122 & $7,12 \%$ \\
\hline Cinamomo & Melia azedarach L. & Meliaceae & Exótica & 96 & $5,6 \%$ \\
\hline Ipê-amarelo & $\begin{array}{l}\text { Tabebuia Alba } \quad \text { (Cham.) } \\
\text { Sandw. }\end{array}$ & Bignoniaceae & Nativa & 91 & $5,3 \%$ \\
\hline Goiabeira & Psidium guava L. & Myrtaceae & Nativa & 73 & $4,3 \%$ \\
\hline Grevilha & Grevillea robusta A. Cunn. & Proteaceae & Exótica & 55 & $3,2 \%$ \\
\hline Leucena & $\begin{array}{l}\text { Leucaena leucocephala } \\
\text { (Lam.) R. de Wit. }\end{array}$ & Fabaceae & Exótica & 54 & $3,15 \%$ \\
\hline Limoeiro & Citrus lemon sp & Rutaceae & Exótica & 53 & $3,1 \%$ \\
\hline Leiteiro-vermelho & Euphorbia cotinifolia L. & Euphorbiaceae & Nativa & 49 & $2,9 \%$ \\
\hline $\begin{array}{l}\text { Jacarandá- } \\
\text { mimoso }\end{array}$ & Jacaranda mimosaefolia Don. & Bignoniaceae & Nativa & 48 & $2,8 \%$ \\
\hline Coqueiro-jerivá & $\begin{array}{l}\text { Syagrus romanzoffiana } \\
\text { (Cham.) Glassm. }\end{array}$ & Palmae & Nativa & 42 & $2,5 \%$ \\
\hline Ficus & Ficus benjamina L. & Moraceae & Exótica & 34 & $1,98 \%$ \\
\hline Tipuana & Tipuana tipu (Benth.) Kuntze & Fabaceae & Exótica & 28 & $1,63 \%$ \\
\hline Nespereira & $\begin{array}{l}\text { Eriobothrya japonica (Thunb.) } \\
\text { Lindl. }\end{array}$ & Rosaceae & Exótica & 27 & $1,6 \%$ \\
\hline Sibipiruna & $\begin{array}{l}\text { Caesalpinea peltophoroides } \\
\text { Benth. }\end{array}$ & Fabaceae & Nativa & 26 & $1,52 \%$ \\
\hline Fícus & Ficus variegata & Moraceae & Exótica & 24 & $1,4 \%$ \\
\hline Pitangueira & Eugenia uniflora L. & Myrtaceae & Nativa & 24 & $1,4 \%$ \\
\hline Araticum & Annona sp & Annonaceae & Nativa & 23 & $1,34 \%$ \\
\hline Amoreira & Morus nigra L. & Moraceae & Exótica & 23 & $1,34 \%$ \\
\hline Fedegoso & $\begin{array}{l}\text { Senna macranthera (Colland.) } \\
\text { Irwin et }\end{array}$ & Fabaceae & Nativa & 18 & $1,04 \%$ \\
\hline Abacateiro & Persea americana Mill. & Lauraceae & Exótica & 17 & $0,98 \%$ \\
\hline Ipezinho & Tecoma stans (L.) ex. Kunth & Bignoniaceae & Exótica & 17 & $0,98 \%$ \\
\hline Aleluia & $\begin{array}{l}\text { Senna multijuga (Rich.) Irwin et } \\
\text { Barn }\end{array}$ & Fabaceae & Nativa & 16 & $0,93 \%$ \\
\hline Pessegueiro & Prunus persica (L.) Batsch & Rosaceae & Exótica & 14 & $0,81 \%$ \\
\hline Aroeira salsa & Schinus molle L. & Anacardiaceae & Nativa & 14 & $0,81 \%$ \\
\hline Sabugueiro & Sambucus nigra L. & Caprifoliaceae & Exótica & 13 & $0,75 \%$ \\
\hline Pata-de-vaca & Bauhinia variegata $\mathrm{L}$. & Fabaceae & Nativa & 12 & $0,7 \%$ \\
\hline Quaresmeira & Tibouchina granulosa Cogn. & $\begin{array}{l}\text { Melastomatacea } \\
\mathrm{e}\end{array}$ & Nativa & 12 & $0,7 \%$ \\
\hline Araçazeira & Psidium littorale L. & Myrtaceae & Nativa & 12 & $0,7 \%$ \\
\hline Falso-ipê & Stenolobium stans (Juss.) & Bignoniaceae & Exótica & 11 & $0,64 \%$ \\
\hline Cerejeira & Eugenia involucrata D.C & Myrtaceae & Nativa & 11 & $0,64 \%$ \\
\hline Paineira & Chorisia speciosa St.Hil. & Bombacaceae & Nativa & 11 & $0,64 \%$ \\
\hline Pingo-de-ouro & Duranta repens var. alba & Verbenaceae & Exótica & 11 & $0,64 \%$ \\
\hline Dedaleira & Lafoensia pacari St. Hil. & Lytraceae & Nativa & 9 & $0,53 \%$ \\
\hline $\begin{array}{l}\text { Eritrina- } \\
\text { candelabro }\end{array}$ & Erythrina speciosa Andrews & Fabaceae & Nativa & 8 & $0,47 \%$ \\
\hline Chorão & Salix babilonica L. & Salicaceae & Exótica & 7 & $0,41 \%$ \\
\hline Cedrinho & Thuja occidentalis L. & Cupressaceae & Exótica & 7 & $0,41 \%$ \\
\hline Acácia-negra & Acacia mearnsii De Willd. & Fabaceae & Exótica & 6 & $0,35 \%$ \\
\hline Cássia-ferrugínea & Cássia ferruginea Schrad. & Fabaceae & Exótica & 6 & $0,35 \%$ \\
\hline Cássia-fístula & Cassia fistula L. & Fabaceae & Exótica & 5 & $0,3 \%$ \\
\hline Cedro & Cedrella fissilis Vell. & Pinaceae & Exótica & 5 & $0,3 \%$ \\
\hline
\end{tabular}




\begin{tabular}{|c|c|c|c|c|c|}
\hline Nome Popular & Nome Científico & Família & Origem & $\mathrm{NI}$ & Fr.\% \\
\hline $\begin{array}{l}\text { Cerejeira-do- } \\
\text { japão }\end{array}$ & Prunus campanulata Maxim. & Rosaceae & Exótica & 5 & $0,3 \%$ \\
\hline Eucalipto & $\begin{array}{l}\text { Eucalyptus camaldulensis } \\
\text { Dehn. }\end{array}$ & Myrtaceae & Exótica & 5 & $0,3 \%$ \\
\hline $\begin{array}{l}\text { Pinheiro do } \\
\text { Paraná }\end{array}$ & $\begin{array}{l}\text { Araucaria angustifolia (Bertol.) } \\
\text { Kuntze }\end{array}$ & Araucariaceae & Nativa & 4 & $0,23 \%$ \\
\hline Cássia-senna & Senna bicapsularis (L.) Roxb. & Fabaceae & Exótica & 4 & $0,23 \%$ \\
\hline Falsa-seringueira & Ficus elastica Roxb. & Moraceae & Exótica & 4 & $0,23 \%$ \\
\hline Laranjeira & Citrus sinensis L. Osbeck. & Rutaceae & Exótica & 4 & $0,23 \%$ \\
\hline Pau-brasil & Caesalpina echinata Lam. & Fabaceae & Nativa & 4 & $0,23 \%$ \\
\hline Acácia mimosa & $\begin{array}{l}\text { Acacia podalyriifolia } \mathrm{A} . \\
\text { Cunningham ex G. Don. }\end{array}$ & Fabaceae & Exótica & 3 & $0,18 \%$ \\
\hline Açoita-cavalo & Luehea divaricata Mart. & Tiliaceae & Nativa & 3 & $0,18 \%$ \\
\hline Ipê-roxo & $\begin{array}{l}\text { Tabebuia avellanedae (Vell.) } \\
\text { Tol. }\end{array}$ & Bignoniaceae & Nativa & 3 & $0,18 \%$ \\
\hline Myrsine & Myrsine coriacea (Sw.) R.Br. & Myrsinaceae & Exótica & 3 & $0,18 \%$ \\
\hline Palmeira imperial & $\begin{array}{l}\text { Roystonea } \quad \text { oleracea(Jacq.) } \\
\text { O.F. Cook }\end{array}$ & Palmae & Exótica & 3 & $0,18 \%$ \\
\hline Pinus & Pinus sp & Pinaceae & Exótica & 3 & $0,18 \%$ \\
\hline Uva-do-japão & Hovenia dulcis Thunb. & Rhamnaceae & Exótica & 3 & $0,18 \%$ \\
\hline Canela-preta & $\begin{array}{l}\text { Nectandra } \quad \text { megapotâmica } \\
\text { (Spreng.) Mez }\end{array}$ & Lauraceae & Nativa & 2 & $0,12 \%$ \\
\hline Canela & Ocotea sp & Lauraceae & Nativa & 2 & $0,12 \%$ \\
\hline Caquizeiro & Diospyros kaki L.F. & Ebenaceae & Exótica & 2 & $0,12 \%$ \\
\hline Cedrilho & & Cupressaceae & Exótica & 2 & $0,12 \%$ \\
\hline Espinheira santa & $\begin{array}{l}\text { Maytenus ilicifolia Mart. ex } \\
\text { Reiss }\end{array}$ & Celastraceae & Exótica & 2 & $0,12 \%$ \\
\hline Flamboiã & Delonix regia (Bojer) Raf & Fabaceae & Exótica & 2 & $0,12 \%$ \\
\hline Mangueira & $\begin{array}{l}\text { Mangifera indica (Schrad.) } \\
\text { Planch. }\end{array}$ & Anacardiaceae & Exótica & 2 & $0,12 \%$ \\
\hline Nim & Azadarachta indica A. J uss. & Meliaceae & Nativa & 2 & $0,12 \%$ \\
\hline Plátano & Platanus sp & Platanaceae & Exótica & 2 & $0,12 \%$ \\
\hline Pinheiro-dourado & Chamaecyparis obtusa cripssii & Cupressaceae & Exótica & 2 & $0,12 \%$ \\
\hline Acácia-prateada & Acácia dealbata Link. & Fabaceae & Exótica & 1 & $0,06 \%$ \\
\hline Boleiro & Alchornea sp & Euphorbiaceae & Nativa & 1 & $0,06 \%$ \\
\hline Branquilho & $\begin{array}{l}\text { Sebastiania klotzschiana } \\
\text { (Baill.) Smith \& Downs }\end{array}$ & Euphorbiaceae & Nativa & 1 & $0,06 \%$ \\
\hline Branquinho & Sapium sp & Euphorbiaceae & Nativa & 1 & $0,06 \%$ \\
\hline Camélia & Camellia japonica & Theaceae & Exótica & 1 & $0,06 \%$ \\
\hline Champá & Michelia champaca L. & Magnoliaceae & Exótica & 1 & $0,06 \%$ \\
\hline Cipreste & Cupressus sp & Cupressaceae & Exótica & 1 & $0,06 \%$ \\
\hline Figueira lira & Ficus lyrata & Moraceae & Exótica & 1 & $0,06 \%$ \\
\hline Figueira mimosa & $\begin{array}{l}\text { Ficus mysorensis Roth ex } \\
\text { Roem. \& Schult }\end{array}$ & Moraceae & Exótica & 1 & $0,06 \%$ \\
\hline Ingá & Inga marginata Willd. & Fabaceae & Nativa & & $0,06 \%$ \\
\hline Ipê-branco & $\begin{array}{l}\text { Tabebuia roseo Alba (Ridl.) } \\
\text { Sand. }\end{array}$ & Bignoniaceae & Nativa & 1 & $0,06 \%$ \\
\hline Jambolão & Syzygium cuminni (L.) Skeels & Myrtaceae & Exótica & 1 & $0,06 \%$ \\
\hline $\begin{array}{l}\text { Jacarandá- } \\
\text { pubérula }\end{array}$ & Jacaranda puberula Cham. & Bignoniaceae & Nativa & 1 & $0,06 \%$ \\
\hline Oliveira & Olea europeaa L. & Oleaceae & Exótica & 1 & $0,06 \%$ \\
\hline Palmeira & & Palmae & Exótica & 1 & $0,06 \%$ \\
\hline Palmeira-leque & Livingstonia chinensis & Palmae & Exótica & 1 & $0,06 \%$ \\
\hline Pau-toucinho & Vernonia sp & Asteraceae & Nativa & 1 & $0,06 \%$ \\
\hline Ponkanzeira & Citrus sp & Rutaceae & Exótica & 1 & $0,06 \%$ \\
\hline Ipê & Tabebuia ochramancea Cham. & Bignoniaceae & Nativa & 1 & $0,06 \%$ \\
\hline
\end{tabular}




\begin{tabular}{llllcc}
$\begin{array}{l}\text { Nome Popular } \\
\text { Viburno }\end{array}$ & $\begin{array}{l}\text { Nome Científico } \\
\text { Viburnum odoratissimum } \\
\text { Gawl. }\end{array}$ & Ker & $\begin{array}{l}\text { Família } \\
\text { caprifoliaceae }\end{array}$ & $\begin{array}{c}\text { Origem } \\
\text { Exótica }\end{array}$ & $\begin{array}{c}\text { NI } \\
1\end{array}$ \\
\hline TOTAL & & & \\
\hline
\end{tabular}

A espécie presente em maior número é Ligustrum lucidum W. T. Aiton da família Oleaceae, conhecido vulgarmente como Ligustro que representa 20,7\% (357 indivíduos) do total das espécies. Essa espécie com potencial invasor deve ser removida e substituída por espécie nativa, gradativamente, pois plantas exóticas invasoras tendem a produzir alterações em propriedades ecológicas essenciais como ciclagem de nutrientes e produtividade vegetal, cadeias tróficas, estrutura, dominância e distribuição (ZILLER, 2001).

A segunda espécie de maior incidência é a Schinus terebinthifolius Raddi. da família Anacardiaceae (Aroeira) com 7,63\%, seguida por Lagerstroemia indica L. da família Lythraceae (Extremosa) com 7,12\%; Melia azedarach L. da família Meliaceae (Cinamomo) com 5,6\%; Tabebuia Alba (Cham.) Sandw. da família Bignoniaceae (Ipêamarelo) com 5,3\%; Psidium guava L. da família Myrtaceae (Goiabeira) com 4,3\%; Grevillea robusta A. Cunn. da família Proteaceae (Grevilha) com 3,2\%; Leucaena leucocaephala (Lam.) R. de Wit. da família Fabaceae Mimosoideae (Leucena) com 3,15\%; Citrus lemon sp da família Rutaceae (Limoeiro) com 3,1\%; e Euphorbia cotinifolia L. família Euphorbiaceae (Leiteiro-vermelho) com 2,9\%.

As 10 famílias com maior freqüência são: Oleaceae (20,7\%), Fabaceae (12\%), Bignoniaceae (10,15\%), Anacardiaceae (8,5\%), Lythraceae (7,6\%), Myrtaceae (7,3\%), Meliaceae (5,7\%), Moraceae (5\%), Rutaceae $(3,4 \%)$ e Proteaceae $(3,2 \%)$.

É possível constatar que apenas a espécie Ligustrum lucidum W. T. Aiton ultrapassa $15 \%$ do total (Tabela 02), excedendo o nível de diversidade sugerido por Biondi (2005), acarretando risco de perdas significativas caso essa espécie seja alvo de pragas e doenças.

Esse levantamento pode demonstrar as relações e os conflitos que envolvem a comunidade e os indivíduos arbóreos, pois além dos 49 indivíduos que não puderam ser identificados devido à poda radical, e de 42 que estavam mortos, aproximadamente $25 \%$ das espécies apresentaram algum tipo de conflito.

Com relação aos tipos de poda encontrados, a poda radical é a mais freqüente com 9,5\% do total de espécies. Algumas acabam morrendo devido à poda, mas as que rebrotam, geralmente crescem deformadas.

Segundo Seitz (1990), na execução de podas, deve ser dada atenção especial à morfologia da base do galho, pois na inserção do galho no tronco principal, distinguemse duas estruturas: a crista na parte superior e o colar na parte inferior da base do 
galho, que são de vital importância para garantir a cicatrização da planta. Segundo Milano e Dalcin (2000), as lesões funcionam como entrada para microrganismos apodrecedores, insetos ou doenças (TABELA 3).

TABELA 3: Classificação dos indivíduos arbóreos do Bairro da Ronda, 2008, de acordo com o tipo de poda.

\begin{tabular}{|c|c|c|}
\hline TIPO DE PODA & $\mathrm{N}^{\circ}$ DE AMOSTRAS & $\%$ \\
\hline Poda leve ruim & 22 & 1,17 \\
\hline Poda pesada boa & 26 & 1,4 \\
\hline Poda pesada ruim & 36 & 2 \\
\hline Não identificados devido a poda radical & 49 & 2,6 \\
\hline Total de indivíduos que sofreram poda & 338 & 18 \\
\hline Total de indivíduos que não sofreram poda & 1.553 & 82 \\
\hline
\end{tabular}

Fonte: Adaptado de Volpe-Filik, Silva e Lima (2007).

Organização: Miranda, 2008.

As raízes das árvores podem causar problemas com calçadas, quebrando-as, dificultando a passagem de pedestres; sarjetas e esgotos podem ser entupidos ou apresentarem dificuldades para manutenção; muros podem ser quebrados e até mesmo derrubados pelas árvores, entretanto, não são as espécies utilizadas que acarretam tais problemas, mas sim, a forma de manejo efetuado que ocasiona esses prejuízos (VOLPE-FILIK, 2009).

A coincidência entre a altura das árvores com a rede elétrica aparece em 10\% das árvores. Segundo alguns autores como Milano e Dalcin (2000), árvores de grande porte podem ser utilizadas sob redes, com restritos problemas e baixa demanda de poda. Contudo a relação árvore e rede elétrica é vista de maneira crítica pela população, sendo apontado nesse trabalho como um conflito em potencial.

O convívio harmonioso entre a população e o "verde" somente se concretizará quando as planificações dos espaços permitirem a presença da vegetação e as arborizações forem efetivamente implantadas, monitoradas e preservadas (SANTOS e TEIXEIRA, 2001).

Analisando o porte das árvores com a largura das calçadas, verificou-se que $85 \%$ das árvores são no máximo de porte médio (até $6 \mathrm{~m}$ ); metade das vias não possui calçadas; a outra metade que possui apresenta pelo menos um indivíduo fora do padrão estabelecido, pois calçadas de $3 \mathrm{~m}$ de largura devem comportar árvores de até $6 \mathrm{~m}$ de altura. 
Com esse levantamento percebe-se a incoerência da Prefeitura Municipal em acrescentar no código de postura o plantio de árvores a cada doze metros sem ao menos delimitar as calçadas, pois este é o primeiro passo para poder indicar o porte de árvore para cada local.

Durante a pesquisa de campo para coleta de dados, 11 vias foram identificadas com potencial para serem arborizadas. Dentre estas, apenas duas não apresentavam limite rua-calçada, as demais possuíam calçadas com $2 \mathrm{~m}$ ou mais de largura e 5 vias não apresentavam nenhum tipo de arborização.

A lógica da arborização em calçadas em que a fachada da casa está diretamente na rua não deve ser a mesma, sendo indicadas espécies arbustivas de pequeno porte nessa circunstância.

Existem casos diferenciados, onde as vias apresentam grande quantidade de árvores, mas apenas em um dos lados, como é o caso das ruas José Pedro Moreira, João Justino Santos e José Camargo Lopes. Já em outras há presença arbórea apenas em certa altura como é o caso da Rua Nina Rodrigues e Professor Cardoso Fontes.

Foi inventariada a arborização viária de outros três bairros em Ponta Grossa: Centro (QUADROS, 2005), Olarias (SILVA, 2006) e Estrela (VILELA, 2007). A tabela 4 apresenta os principais dados extraídos dos quatro inventários.

TABELA 4: Arborização viária inventariada para quatro bairros na cidade de Ponta Grossa

\begin{tabular}{|c|c|c|c|c|c|c|c|c|c|}
\hline BAIRRO & $\begin{array}{c}\mathrm{N}^{0} \\
\mathrm{DE} \\
\text { VIAS }\end{array}$ & $\begin{array}{c}\mathrm{N}^{0} \mathrm{DE} \\
\text { INDIVÍDUOS } \\
\text { ARBÓREOS }\end{array}$ & $\begin{array}{c}\mathbf{N}^{0} \mathrm{DE} \\
\text { ESPÉCIES }\end{array}$ & $\begin{array}{c}\mathrm{N}^{0} \mathrm{DE} \\
\text { INDIVÍDUOS } \\
\text { NATIVOS }\end{array}$ & $\begin{array}{c}\mathrm{N}^{\circ} \mathrm{DE} \\
\text { INDIVÍDUOS } \\
\text { EXótICOS }\end{array}$ & $\begin{array}{c}\mathrm{N}^{\circ} \mathrm{DE} \\
\text { FAMíLIAS }\end{array}$ & $\begin{array}{c}\text { ESPÉCIE } \\
\text { COM MAIOR } \\
\text { FREQUENCIA }\end{array}$ & ALFA & $\begin{array}{c}\text { ARVI } \\
\mathrm{Km}\end{array}$ \\
\hline CENTRO & 38 & 1073 & 32 & 196 & 654 & 15 & Extremosa & 10,3 & 25 \\
\hline OLARIAS & 69 & 838 & 46 & 421 & 416 & 22 & Ligustro & 15,5 & 24 \\
\hline ESTRELA & 58 & 1265 & 73 & 506 & 759 & 29 & Extremosa & 23,0 & 41 \\
\hline RONDA & 85 & 1891 & 86 & 658 & 1055 & 35 & Ligustro & 25,9 & 55 \\
\hline
\end{tabular}

Fonte: Quadros (2005); Silva (2006) e Vilela (2007). Organização: Miranda, 2008.

A partir dos dados da tabela 4, foi analisado o índice de diversidade de Margalef de cada bairro, onde o bairro da Ronda apresentou a maior diversidade entre os bairros analisados, seguido respectivamente pelos bairros Estrela, Olarias e o Centro. Os quatro bairros apresentaram alto índice de diversidade, porém, apenas no bairro de Olarias há predominância de espécies nativas sobre as exóticas.

O índice de similaridade de Jaccard é considerado alto quando acima de 50\% e este resultado só foi obtido entre os bairros de Olarias e Ronda com exatamente $50 \%$ 
de similaridade. O Centro da cidade foi o que apresentou menor similaridade com o bairro da Ronda: 28\%. Estrela e Ronda apresentaram similaridade de 37\% entre si.

Foram percorridos 34,2 quilômetros de vias no bairro da Ronda, obtendo-se um índice de abundância de 55 árvores por quilômetro de rua. Outros trabalhos demonstram um valor de 41 árvores por km de rua no bairro Estrela (VILELA, 2007); 25 no Centro da cidade (QUADROS, 2005) e 24 no bairro de Olarias (SILVA, 2006). Esses dados demonstram que os quatro bairros inventariados possuem uma elevada diversidade e abundância, mesmo sem planejamento arbóreo.

\section{CONCLUSÃO}

Os resultados do levantamento quantitativo revelam que o bairro da Ronda apresenta alto índice de diversidade e abundância, entretanto, não houve planejamento para o plantio das árvores no bairro, pois estas se encontram mal distribuídas.

Assim como no Bairro Estrela e no Centro da cidade, no Bairro da Ronda, predominam as espécies exóticas, sendo as mais frequentes, nos quatro bairros inventariados, o Ligustrum lucidum var. japonicum (Ligustro) e a Lagerstroemia indica L. (Extremosa). Quanto às espécies nativas, a mais frequente é a Schinus terebinthifolius Raddi. (Aroeira).

O levantamento qualitativo demonstrou os conflitos que envolvem a comunidade e os indivíduos arbóreos, pois $25 \%$ dos indivíduos apresentam algum tipo de conflito, muitos destes, devido à manutenção incorreta.

\section{REFERÊNCIAS BIBLIOGRÁFICAS:}

BALENSIEFER, M. Poda em arborização urbana. Curitiba: ITCF, 1987. 27 p.

BIONDI, D.; ALTHAUS, M. Árvores de rua de Curitiba: cultivo e manejo. Curitiba: FUPEF, 2005. 182 p.

BORTOLETO, S. Inventário Quali-Quantitativo da Arborização Viária da Estância de Águas de São Pedro - SP. 2004, 98f. Dissertação (Mestrado em agronomia: Fitotecnia). Escola Superior de Agricultura Luiz Queiroz, Universidade de São Paulo, São Paulo.

CAVALHEIRO, F. Urbanização e alterações ambientais. In: TAUK, S. (org.) Análise Ambiental: uma visão multidisciplinar. São Paulo: UNESP/FAPESP, p. 88-99, 1991. 
COSTA, E.C; LINK, D; MEDINA, L.D. de. Índice de Diversidade para entomofauna da Bragatinga (Mimosa scabrella Benth.), Ciencia Florestal, Santa Maria, v.3, n.1, p. 6575, 1993.

FARIA, J. L. G. ; MONTEIRO, E. A. ; FISCH, S. T. V. Arborização de vias públicas do município de Jacareí-SP. Revista Sociedade Brasileira de Arborização Urbana, Piracicaba, v. 2, n.4, dez. 2007, p. 20-33.

GARCIA, P.O.; LOBO-FARIA, P.C. Metodologias para Levantamentos da Biodiversidade Brasileira, 2007, p. 14-18. Universidade Federal de Juiz de Fora. Consultado na Internet, em 24 out 2008. Disponível em: ttp://www.ecologia.ufjf.br/admin/upload/File/Paulo_Garcia.pdf.

IBGE (Instituto Brasileiro De Geografia E Estatística). Cidades, 2008. Disponível em: www.ibge.gov.br, Acesso em: 20 de Outubro de 2008.

LORENZI, H.; SOUZA, H. M. de; TORRES, M. A.V.; BACHER, L. B. Àrvores Exóticas no Brasil: Madereiras, Ornamentais e Aromáticas. Nova Odessa: Plantarum, 2003. $384 \mathrm{p}$.

MILANO, M.S; DALCIN, E.C. Arborização de vias públicas. Rio de Janeiro. Light, 2000. $226 \mathrm{p}$.

PREFEITURA MUNICIPAL DE PONTA GROSSA. PLANO DIRETOR (Coletânea da Legislação), Ponta Grossa, 2006. Disponível em: www.pontagrossa.pr.gov.br. Acesso em: 24 de outubro de 2008.

PREFEITURA MUNICIPAL DE SÃO PAULO. Manual técnico de poda de árvores. Secretaria Municipal do Verde e do Meio Ambiente, 2006. p.16-22

QUADROS, G. P. Arborização Urbana na Área Central de Ponta Grossa: Implantação, Preservação e Monitoramento - 2005. 128 p. Ponta Grossa, 2005. Trabalho de Conclusão de Curso (Graduação em Geografia) - Universidade Estadual de Ponta Grossa.

ROSSATO, D.R; TSUBOY, M.S.F; FREI, FERNANDO. Arborização Urbana na cidade de Assis - SP: Uma abordagem quantitativa. Revista Sociedade Brasileira de Arborização Urbana, Piracicaba, v. 3, n.3, p. 1-16, dez. 2008.

SANTOS, N. R. Z.; TEIXEIRA, I. F. Arborização de Vias Públicas: Ambiente $x$ Vegetação. RS: Clube da árvore, 2001. 135p.

SEITZ, R.A. Considerações sobre a poda de árvores na arborização urbana. In: Encontro Nacional sobre Arborização Urbana, 3, 1990. Anais. Curitiba: FUPEF. 1990. p.87-100.

SILVA, R.K.D. Arborização Urbana Viária no Bairro de Olarias, Ponta Grossa/PR. Ponta Grossa, 2006. 91 p. Trabalho de Conclusão de Curso (Graduação em Geografia) - Universidade Estadual de Ponta Grossa. 
VILELA, J. C. Levantamento Quantitativo e Qualitativo de Individuos Arbóreos Presentes nas vias do Bairro Estrela em Ponta Grossa/Pr. Ponta Grossa 2007. 98 p. Trabalho de Conclusão de Curso (Graduação em Geografia) - Universidade Estadual de Ponta Grossa.

TAKEDA, I.J.M.; R.S. MORO; R. KACZMARECH; L.C.M. BAHLS; M.V. BOURGUIGNON \& E. SCHARDOSIN. Levantamento Florístico do Parque Municipal Boca da Ronda, Ponta Grossa, PR. Publicatio UEPG, sér. Ciências Biológicas, v.4, n.1, p. 49-56, 1998.

VOLPE-FILIK, A. Trincas nas calçadas e espécies muito utilizadas na arborização: comparação entre Sibipiruna ( Caesalpinia pluviosa Dc.) e Falsa-murta (Murraya paniculata (L.) Jacq.), no município de Piracicaba/SP. Piracicaba, p. 96, 2009. Tese (Doutorado) - Escola Superior de Agricultura Luiz de Queiroz.

VOLPE-FILIK, A.; SILVA, L. F. da; LIMA, A.M.L.P. Avaliação da Arborização de Ruas do bairro de São Dimas na cidade de Piracicaba/SP através de Parâmetros Qualitativos. Revista da Sociedade Brasileira de Arborização Urbana, vol 2, n.1, p. 34- 43, 2007.

ZILLER, S. R. Os processos de degradação ambiental originados por plantas invasoras. Revista Ciência Hoje. n.178, p. 77-79, dez. 2001. 